\title{
In silico investigations of possible routes of assembly of ORF 3a from SARS-CoV
}

\author{
Hao-Jen Hsu • Wolfgang B. Fischer
}

Received: 27 November 2010 / Accepted: 12 April 2011 /Published online: 4 May 2011

(C) Springer-Verlag 2011

\begin{abstract}
ORF 3a of human severe acute respiratory syndrome corona virus (SARS-CoV) has been identified as a 274 amino acid membrane protein. When expressed in Xenopus oocytes the protein forms channels. Based on bioinformatics approaches the topology has been identified to include three transmembrane domains (TMDs). Since structural models from experiments are still lacking, computational methods can be challenged to generate such models. In this study, a 'sequential approach' for the assembly is proposed in which the individual TMDs are assembled one by one. This protocol is compared with a concerted protocol in which all TMDs are assembled simultaneously. The role of the loops between the TMDs during assembly of the monomers into a bundle is investigated. Molecular dynamics simulations for $20 \mathrm{~ns}$ are performed as a short equilibration to assess the bundle stability in a lipid environment. The results suggest that bundles are likely with the second TMD facing the putative pore. All the putative bundles show water molecules trapped within the lumen of the pore with only occasional events of complete crossing.
\end{abstract}

Keywords Docking Ion channel $\cdot$ Membrane protein . Molecular dynamics $\cdot$ Protein assembly $\cdot 3 \mathrm{a}$ of SARS-CoV

Electronic supplementary material The online version of this article (doi:10.1007/s00894-011-1092-6) contains supplementary material, which is available to authorized users.

H.-J. Hsu • W. B. Fischer $(\square)$

Institute of Biophotonics, School of Biomedical

Science and Engineering, National Yang-Ming University,

Taipei, Taiwan

e-mail: wfischer@ym.edu.tw

\section{Introduction}

SARS-CoV has a single positive strand RNA genome carrying 14 open reading frames (ORFs), encoding viral structural proteins (such as spike, envelope, membrane, and nucleocapsid proteins), replicases, and accessory proteins [1]. ORF 3a of SARS-CoV is identified as a 274 amino acid (a.a.) structural protein, which is located between $\mathrm{S}$ and $\mathrm{E}$ proteins [2]. ORF 3a protein harbors three transmembrane domains (TMDs) at its N-terminal side and a longer intracellular C-terminal region of about 148 amino acids. The central region of $3 \mathrm{a}$ protein consists of cysteine-rich domain (a.a. 127-133), $\operatorname{Yxx} \varphi$ domain (a.a. 160-163) and diacidic domain (a.a. 171-173) [1-3]. 3a protein is suggested to form a homotetramer via monomer disulfide bridges (Cys-133 [4]) forming a dimer and the noncovalent assembly of two of the dimers forming the functional tetramer [5]. Structural information about the protein or its biological role in the cellular life cycle of the virus is still in the dark.

Viral channel forming proteins, have also been found for other viruses [6-8], such as M2 from influenza A [9-12], Vpu from HIV-1 [13, 14], 8a from SARS-CoV [5, 15], protein $\mathrm{p} 7$ from HCV [16, 17], 2B from Polio virus [18, 19] $3 \mathrm{a}$ and $\mathrm{E}$ proteins from SARS-CoV [4, 20], just to mention some of them, are also known to homo-oligomerize. The number of TMDs increases going from M2, Vpu and 8a, with a single TMD per monomer, to two TMDs for $\mathrm{p} 7$ and $2 \mathrm{~B}$ and finally to three TMDs for $3 \mathrm{a}$. Albeit the emergence of more and more structural information derived from experiments (for a review see [7, 21]) modeling the assembly of the proteins is still a challenge.

In general, a two-staged mechanism for helix-bundle membrane protein folding is suggested [22]: (i) the fold of the membrane domain into its secondary structure, a helix, 
(ii) the assembly of the inserted helices in the membrane. This model is expanded to include a third stage in which co-factor insertion, folding of the extramembrane parts and quaternary assembly is included [23]. This model description also holds on the energy landscape for membrane protein folding [24]. Along the line of this mechanism some computational assembly protocols are designed by using rigid body movements to explore energy landscapes [2527]. These methods allow improving the quality of sampling conformational space via the step width of structure placements. Another approach reported in the literature includes extended replica exchange molecular dynamics simulations to assembly homooligomers [28]. Another almost unbiased approach is achieved if helices can freely diffuse within the lipid bilayer. This approach has been demonstrated for the assembly of TMDs into dimers using coarse-grained MD simulations techniques [29]. Still the full story of membrane protein folding remains to be elucidated [30].

Previous work proposed an assembly methodology to search the conformational space of all possible assemblies for the preferable structure, taking symmetry considerations into account [31]. The methodology has been tested on M2 from influenza A showing agreement with experimentally derived structure. The structure of protein $3 \mathrm{a}$ from SARS-CoV was first time predicted based on this methodology. Although it's good agreement with the experiments, the mechanism of simultaneous assembly is still hard to imagine. One idea proposed herein is that there are two assembly methods, concerted and sequential [32], for comparison to search the most preferable bundle models of $3 \mathrm{a}$ from SARS-CoV. Loops between the transmembrane domains (TMDs) are also predicted for comparison. MD simulations of possible bundle models are performed for confirmation.

\section{Computational methods}

Ideal helices, of the TMDs of 3a [31], TMD1 ${ }_{39-59}\left(\mathrm{AS}^{40}\right.$ LPFGWLVIGV $^{50}$ AFLAVFQSA), TMD2 $79-99$ (FI ${ }^{80}$ CNLLLLFVTI $^{90}$ YSHLLLVAA), and TMD3 $_{105-125}$ (FLY LYA $^{110}$ LIYFLQCINA $^{120}$ CRIIM), were generated with backbone dihedrals of $\varphi=-65^{\circ}$ and $\phi=-39^{\circ}$ using the program MOE (Molecular Operation Environment, www. chemcomp.com) and its integrated protein builder.

\section{Equilibration of the TMDs}

Each of the ideal helix was embedded into a fully hydrated POPC lipid bilayer (16:0-18:1 diester PC, 1-palmitory-2oleoyl-sn-glycero-3-phospho-chloine) for $10 \mathrm{~ns}$ MD simulation to derive a relaxation of the conformation. POPC topology parameters were taken from [33]. And the bilayer has undergone a $70 \mathrm{~ns}$ MD simulation to be equilibrates as much as possible [34]. After insertion a stepwise energy minimization and equilibration protocol was adapted [34]. The system was heated gradually to $310 \mathrm{~K}$ in $500 \mathrm{ps}$, and then five stages of equilibration were performed where all the heavy atoms of the bundle were restrained in their initial positions by applying a harmonic force in $\mathrm{x}, \mathrm{y}$ and $\mathrm{z}$ directions $(1000,500,250,100$, and $10 \mathrm{~kJ} / \mathrm{mol} / \mathrm{nm})$. These runs were to adjust the lipid to the inserted bundle.

Prior to assembly

A principal component analysis (PCA) over the backbone atoms of all frames of the last $3 \mathrm{~ns}$ of each of the TMDs has been done. A structure was calculated averaging over the first few eigenvectors. PCA was accomplished using the program g_covar from the GROMACS-4.0.5 package. Rotational and translational motions were removed by fitting the peptide structure of each time frame to the starting structure.

\section{Assembly}

The equilibrated TMDs derived from MD simulations are used to generate tetrameric assemblies via various routes (Fig. 1).

\section{Monomer assembly}

(1) Sequential assembly

The helical backbone structure from PCA analysis is aligned along the z-axis. Two methods were used to assemble the monomer (Fig. 1): sequential 1 (Seq1, assembly from $\mathrm{C}$-terminus to $\mathrm{N}$-terminus) and sequential 2 (Seq2, assembly from N-terminus to Cterminus). For Seq1, TMD3 and TMD2 were assembled first becoming a new TMD unit (TMD3 + TMD2). This unit is consequently assembled with TMD1 to form a monomeric subunit ((TMD3 + TMD2) + TMD1). Herein, one of the TMDs was fixed and the second TMD was rotated around the other TMD (rotational angle 2) and around its own helical axis (rotational angle 1), then tilted and translated to the other TMD. The same rotation protocol was adopted for the generated unit of two TMDs being kept fixed whilst the third TMD was rotated around the unit. Similarly, for Seq2, TM1 is first assembled with TM2 to form a new TMD unit followed by the assembly with TMD3 to form a monomer ((TMD1 + TMD2) + TMD3).

(2) Simultaneous assembly

In the simultaneous assembly three TMDs are assembled in a concerted fashion to form a monomeric subunit [31]. This assembly method is hither forth 
Fig. 1 Flowchart of the steps involved forming the tetrameric assemblies. Single TMDs are either assembled in a sequential (Seq1, Seq2) or concerted (Sim) manner to form monomeric structures. The monomers are assembled into tetramers $(\mathrm{T})$ either with loops (L) or without prior to assembly

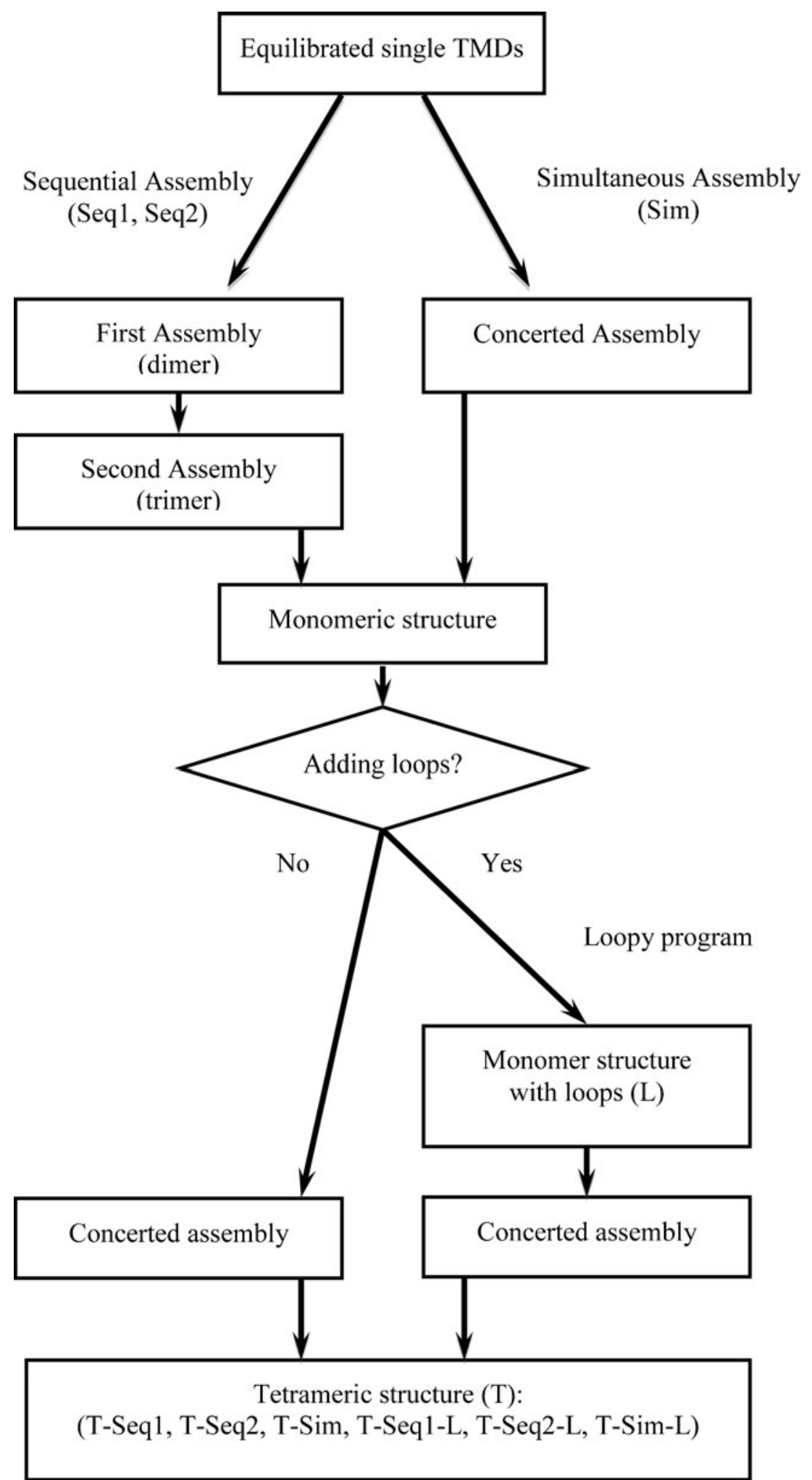

referred to as Sim. According to the symmetry all single TMD backbones were rotated around their own helical axis in the same sense with respect to the central pore axis, and were also tilted simultaneously. The construction of a trimer followed basic geometry with inter-helical separation angles of $120^{\circ}$. Besides, to cover all weak and tight packing inter-helical distances in the range from 8.5 to $12.0 \AA$ were sampled for each monomer assembly method. The distance data are referred to as the distance between the center of mass of each TMD. 
(3) Adding loops

Monomeric models 'with loops' obtained their 'loops' using the program Loopy [35, 36]. Two loops (loop1: residues 60-78; loop2: residues 100-104) were added on the monomeric subunit accordingly. The lowest energy structures are named Seq1-L, Seq2L, Sim-L.

\section{Tetramer assembly}

The monomeric subunits were assembled into a tetrameric bundle using the Sim protocol. According to the protocol used for the monomeric subunit the tetrameric bundles are referred to as T-Seq1, T-Seq2 and T-Sim (with added loops T-Seq1-L, T-Seq2-L and T-Sim-L). The interhelical separation angle was set to $90^{\circ}$ and the interhelical distances sampled in the range of 18 to $24 \AA$ to cover all possible packing modes.

To further sample conformational space, several degrees of freedom were varied systematically, such as interhelical distance by $0.25 \AA$, rotational angle by $5^{\circ}$, and tilt angle (hither forth called tilt) by $2^{\circ}$. After each positioning, side chain atoms were reconstructed, followed by an energy minimization of 5 steps of steepest descend and 10 steps of conjugated gradient. Potential energy of each conformation/ position was evaluated based on the Amber 94 force field in an implicit lipid environment characterized by a dielectric constant of $\varepsilon=2$. With this protocol hundreds of thousands of different conformations were generated.

\section{MD simulations}

The selected tetrameric bundle was then embedded into a POPC lipid bilayer system by removing overlapping lipids and waters molecules. After energy minimization, 4 or 16 $\mathrm{Cl}^{-}$ions were added to compensate for the positive net charge of each monomer. Finally, the whole system without adding loops to the bundle consisted of the bundle (2624 atoms), 462 POPC- and 14616 SPC-water molecules including $4 \mathrm{Cl}^{-}$(70500 atoms in total). The system with added loops consisted of the 3640 bundle atoms, 462 POPC-, and 14604 SPC-water molecules, including $16 \mathrm{Cl}^{-}$ (71492 atoms in total). The MD simulation protocol was as followed, after energy minimization (see above), $20 \mathrm{~ns}$ production runs were carried out without any constraint on the bundle.

GROMACS-4.0.5 with the Gromos96 (ffG45a3) force field was used for the simulations. The simulations were conducted in the NPT ensemble employing the velocityrescaling thermostat at constant temperature $310 \mathrm{~K}$, and $1 \mathrm{bar}$. The temperature of the protein, lipid and the solvent were separately coupled with a coupling time of $0.1 \mathrm{ps}$.
Semi-isotropic pressure coupling was applied with a coupling time of $0.1 \mathrm{ps}$ and a compressibility of $4.5 \mathrm{x}$ $10^{-5} \mathrm{bar}^{-1}$ for the xy-plane as well as for the $\mathrm{z}$-direction. Long range electrostatics calculated using the particlemesh Ewald (PME) summation algorithm with grid dimensions of $0.12 \mathrm{~nm}$. Lennard-Jones and short-range Coulomb interactions were cut off at 1.4 and $0.8 \mathrm{~nm}$, respectively.

The simulations were run on a DELL Precision T5400 workstation, and a cluster consisting of 32 cores (Xeon $2.26 \mathrm{GHz}$ ). Plots and pictures were generated using xmgrace, VMD and MOE.

\section{Results}

Equilibration

All three TMDs show stable root mean square deviation (RMSD) values over the entire duration of the simulation. Within the last $4 \mathrm{~ns}$ of the $10 \mathrm{~ns}$ simulation values between 0.1 and $0.2 \mathrm{~nm}$ are calculated identifying that the short run deliver reasonably equilibrated structures (Fig. 2a). The root mean square fluctuation (RMSF) of the individual residues of the TMDs shown in Fig. $2 b$ is indicative for low dynamic of the amino acids with higher fluctuation at either end of the TMDs. The residues of the core region of the TMD, albeit at very low level, exhibit slightly higher dynamics than the residues in the head group region (appr. residues $10-25$ and $55-70$ ) giving the graph a w-like shape. A sequence of residues from Asn- 82 to Leu- 85 and around Leu-94 to Leu-96 of TMD2 shows a localized area of larger RMSF values.

\section{Assembly}

\section{Generation of the monomer}

Analysis of the energetic of the monomer assemblies (Suppl. Fig. 1) reveals mostly some close clustering of lowest values independent of the sequence used. Using the first part of Seq1, assembling TMD2 and TMD3, reveals a dimer with lowest energy of $-503.6 \mathrm{kcal} \mathrm{mol}^{-1}$ (Table 1 and Suppl. Fig. 1a). Assembling the third TMD, TMD3, results in two low energy structures calculated with values of $-878.1 \mathrm{kcal} \mathrm{mol}^{-1}$ and $-865.12 \mathrm{kcal} \mathrm{mol}^{-1}$ and interhelical distances of 1.2 and $1.15 \mathrm{~nm}$, respectively (Suppl. Fig. 1b). Both structures are separated by their individual rotational angles but adopt the same tilt direction of $-2^{\circ}$ and $-10^{\circ}$, respectively.

Seq2 reveals a dimer of TMD1 and TMD2 of $-349.6 \mathrm{kcal}$ $\mathrm{mol}^{-1}$. Adding TMD3 results in a monomer of $-863.5 \mathrm{kcal}$ $\mathrm{mol}^{-1}$, with an interhelical distance of $1.175 \mathrm{~nm}$. 

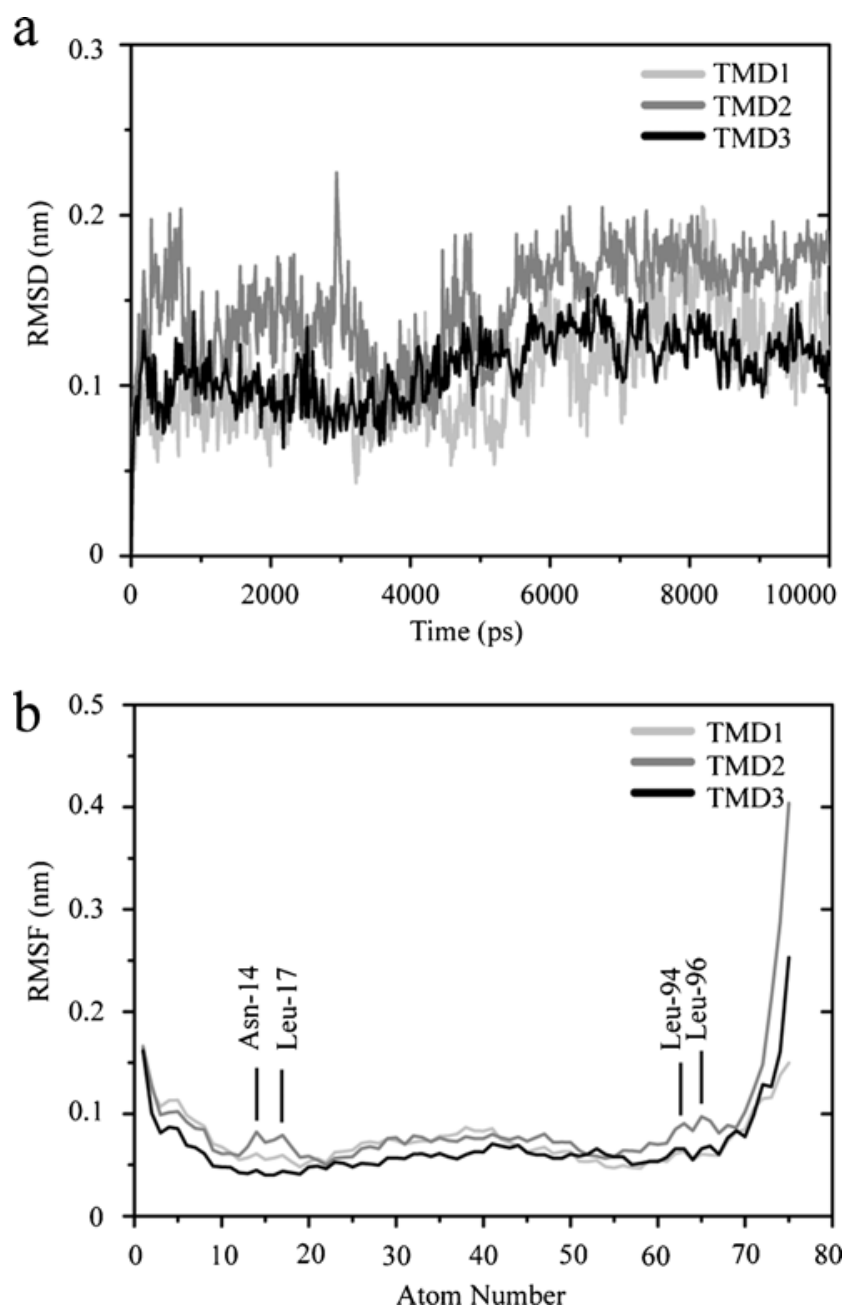

Fig. 2 Root mean square deviation (RMSD) of the $\mathrm{C} \alpha$ backbones of the single TMDs, TMD1, TMD2 and TMD3, referring to the respective starting structure (a). Root mean square fluctuation (RMSF) of the atoms of the amino acids (b). The TMDs are overlaid so that the atom numbers match for each TMD. Values for TMD1 are shown in light gray, those for TMD2 in gray and the values for TMD3 in black
Finally for Sim the lowest energy structure $(-730.5 \mathrm{kcal}$ $\left.\mathrm{mol}^{-1}\right)$ is clearly distinct from the second lowest $\left(-654.8 \mathrm{kcal} \mathrm{mol}^{-1}\right.$ ) by $75.7 \mathrm{kcal} \mathrm{mol}^{-1}$ (data not shown). For these two structures the rotation difference of TMD2 is of up to $40^{\circ}$ and with an opposite tilt direction $\left(-4^{\circ}\right)$ than the second lowest $\left(+4^{\circ}\right)$. Similar to the monomer Seq1 the lowest energy structure has a hydrophobic pore and therefore the second lowest monomer is considered further. The interhelical distance of the second lowest structure is $1.075 \mathrm{~nm}$.

The monomeric structure from Seq1 (Fig. 3a) exhibits a hydrophilic stripe, which is due to residues of TM3 (Tyr109, Tyr-113, Gln-116, and Asn-119) spanning the entire TM stretch. Residues like His-93, Tyr-89 and Asn-82 of TMD2 join toward the same direction. The monomeric structure assembled from Seq2 indicates two hydrophilic stripes, one from Ser-92, His-93, Thr-89, and Asn-82 (all TMD2), and the other from Tyr-109, Tyr-113, Gln-116, and Arg-122 (all TMD3) (shown in Fig. 3b). Similar to Seq1, Sim reveals a single line of hydrophilic residues due to hydrophilic residues of TMD3 (Fig. 3c).

\section{Tetramer assembly without loops}

Assembling T-Seq1 a structure with a minimum energy $\left(-4710.72 \mathrm{kcal} \mathrm{mol}^{-1}\right.$, Table 2) is obtained for intermonomer distance from the centers of mass of the monomers of $2.375 \mathrm{~nm}$ (Suppl. Fig. 2, I). The structure adopts a rotational angle of $320^{\circ}$ and a tilt of $9^{\circ}$. TM2 is the pore lining with only one hydrophilic residue Tyr 91 (highlighted in Fig. 4a) facing the pore.

Alignment of T-Seq2 shows a Lennard-Jones type pattern for the low energy values with the lowest value $-4724.84 \mathrm{kcal} \mathrm{mol}^{-1}$ of $2.15 \mathrm{~nm}$ interhelical distance (Suppl. Fig. 2, II). Although in T-Seq1 TMD2 is facing

Table 1 Lowest and second lowest energy structures of the dimer and finally the monomeric structures. Data represent the interhelical distance, rotational angle of each of the individual TMDs and the averaged (overall TMDs) tilt angle, as well as the energy calculated with MOE

\begin{tabular}{|c|c|c|c|c|c|c|}
\hline Method & Distance (nm) & Angle $1\left(^{\circ}\right)$ & Angle $2\left(^{\circ}\right)$ & Angle $3\left(^{\circ}\right)$ & Tilt $\left(^{\circ}\right)$ & Energy $(\mathrm{kcal} / \mathrm{mol})$ \\
\hline $\begin{array}{l}\text { Seq1 } \\
(\text { TMD3 + TMD2) }\end{array}$ & 1.0 & 40 & 340 & & 8 & -503.6 \\
\hline Seq1 & 1.20 & 260 & 220 & & -2 & -878.1 \\
\hline$((\mathrm{TMD} 3+\mathrm{TMD} 2)+\mathrm{TMD} 1)$ & 1.15 & 180 & 240 & & -10 & -865.1 \\
\hline $\begin{array}{l}\text { Seq2 } \\
(\mathrm{TMD} 1+\mathrm{TMD} 2)\end{array}$ & 0.95 & 340 & 300 & & 0 & -349.6 \\
\hline $\begin{array}{l}\text { Seq2 } \\
((\mathrm{TMD} 1+\mathrm{TMD} 2)+\mathrm{TMD} 3)\end{array}$ & 1.175 & 0 & 40 & & 2 & -863.5 \\
\hline Sim & 1.075 & 60 & 180 & 340 & -4 & -730.5 \\
\hline (TMD1 + TMD2 + TMD3) & 1.075 & 40 & 100 & 80 & 4 & -654.8 \\
\hline
\end{tabular}



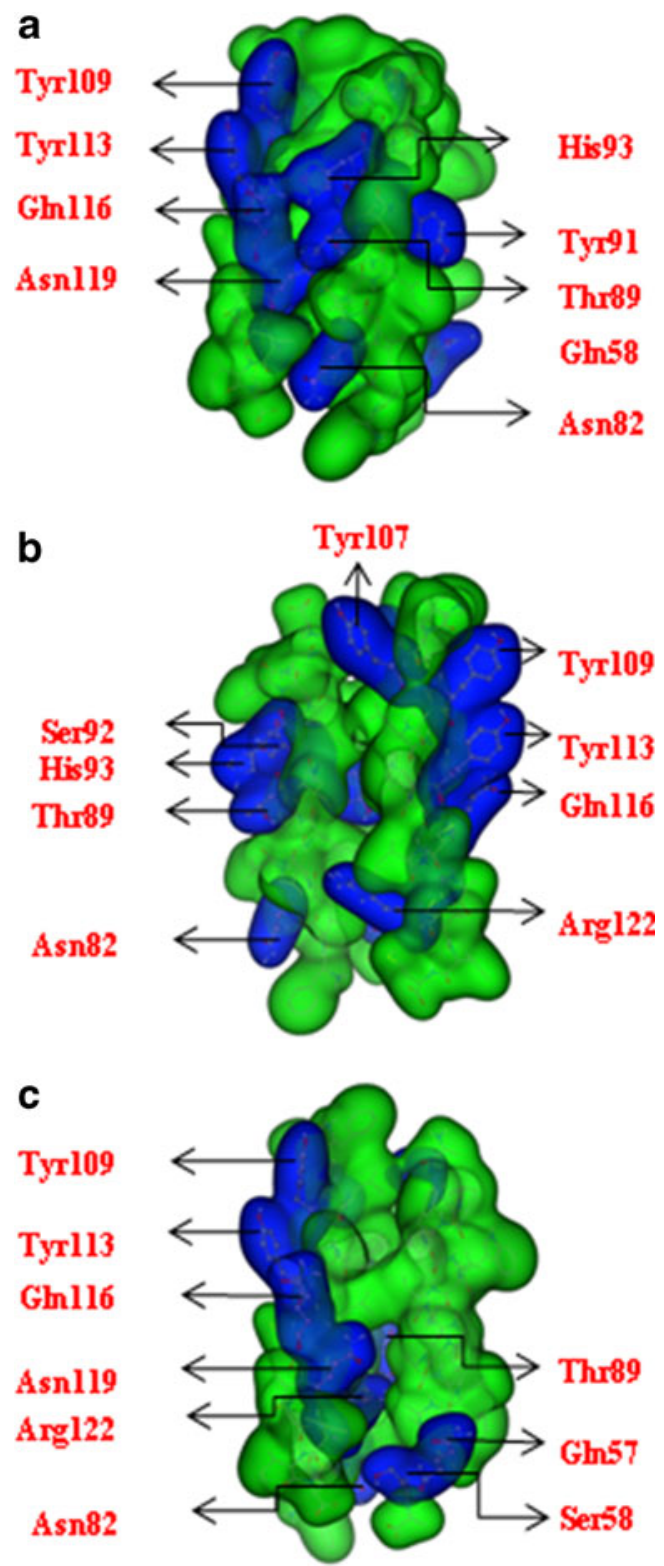

Fig. 3 Monomers according to the assembly protocol: Seq1 (a), Seq2 (b) and $\operatorname{Sim}$ (c). Hydrophilic residues are highlighted in blue, hydrophobic residues in green. All models are drawn in a 'Gaussian Contact' illustration (MOE)

the pore, similar to T-Seq2, the rotational angle is different in T-Seq2, leading to more hydrophilic residues inside the pore lumen (Asn-82, Thr-89, Ser-92, and His93, Fig. 4b).

Alignment of T-Sim derives a lowest energy structure of $-4294.2 \mathrm{kcal} \mathrm{mol}^{-1}$ with an inter monomer distance of $2.1 \mathrm{~nm}$ (Fig. 4c). A second low energy model (see Suppl. Fig. 2, III) does not expose any hydrophilic residues into the pore. In T-Sim TMD3 is pore lining, with several hydrophilic residues facing the pore (Tyr-109, Tyr-113, Gln-116, and Asn-119).
Tetramer assembly with added loops

In another approach the monomeric units are assembled in the presence of the loops between TMD1 and TMD2 as well as between TMD2 and TMD3. Assembling four copies of the Seq1-L monomer delivers a low energy structure with distances of around $2.025 \mathrm{~nm}\left(-5596.99 \mathrm{kcal} \mathrm{mol}^{-1}\right.$, T-Seq1-L) (Table 2). In T-Seq1-L bundle TMD2 is pore lining with Tyr-91 inside the pore lumen and His-93 facing outside the pore (Fig. 4d).

Assembling Seq2-L into a tetramer shows a low energy model with an monomer distance of $2.2 \mathrm{~nm}(-6136.76 \mathrm{kcal}$ $\mathrm{mol}^{-1}$ ), and a tilt angle of $-36^{\circ} \mathrm{T}-\mathrm{Seq} 2-\mathrm{L}$ is shown in Fig. 4e with two hydrophilic residues, Thr-89 and His-93, of TMD2 face the pore.

Screening the energy landscape of Sim-L, the model with the lowest energy $\left(-5543 \mathrm{kcal} \mathrm{mol}^{-1}\right.$, T-Sim-L) has an inter monomer distance of $2.2 \mathrm{~nm}$ (data not shown). The tilt of its monomers adopts $21^{\circ}$. The lowest energy bundle, TSim-L, exposes hydrophilic residue Tyr 91 of TMD2 to the pore (Fig. 4f). Although the T-Sim-L is similar to T-Seq1-L with one with Tyr 91 inside the pore and His 93 outside the pore, the pore of T-Sim-L has more hydrophilic residues pointing into the pore than T-Seq1-L.

Comparing the energy values amongst the monomers reveals that Seq1 and Seq2 generate monomers with minimum energies around $-860 \mathrm{kcal} \mathrm{mol}^{-1}$ to $-880 \mathrm{kcal}$ $\mathrm{mol}^{-1}$ whilst Sim generates monomers with higher values of around $-650 \mathrm{kcal} \mathrm{mol}^{-1}$ and $-730 \mathrm{kcal} \mathrm{mol}^{-1}$ (Suppl. Fig. 1). The bundle models reflect this trend independent of the presence of the loops (Suppl. Fig. 2). Whilst energies for bundles similar to T-Seq1 and T-Seq2 both are calculated to be around $-4700 \mathrm{kcal} \mathrm{mol}^{-1}$, the respective values for bundles similar to T-Seq1-L and T-Seq2-L show lower values for the bundles similar to T-Seq2-L: around $-6100 \mathrm{kcal} \mathrm{mol}^{-1}$ (T-Seq2-L) versus $-5600 \mathrm{kcal} \mathrm{mol}^{-1}$ (TSeq1-L). The energy values for the bundles similar to TSeq1-L are indistinguishable from those for bundles according to T-Sim-L. As a result, T-Seq2-L is the bundle with the low interaction energy.

\section{MD simulations}

All six tetrameric assembled structures of $3 \mathrm{a}$ from SARS $\mathrm{CoV}$ (Fig. 4) are run for $20 \mathrm{~ns}$ of a MD simulation embedded into a bilayer of POPC to equilibrate the structures further. The RMSD plot for $\mathrm{C} \alpha$ atoms of the tetrameric bundles without loops is shown in Fig. 5a. The data reveals a progressive rising for all structures and consequent stable fluctuation after the first $5 \mathrm{~ns}$ (Fig. 5a, I). All RMSD values remain in a range of $0.1-0.3 \mathrm{~nm}$. In order to know how each TMD affects the stabilization of the structure, the RMSD of each TMD for the three bundles 
Table 2 Lowest energy structures of the tetramer generated from monomers listed in

Table 1. Data represent inter monomer distances, rotational and tilt angles, as well as the interaction energy calculated with MOE. The TMD of each of the monomer facing the pore is listed for each of the tetramers

\begin{tabular}{llllll}
\hline Method & Distance $(\mathrm{nm})$ & Angle $\left(^{\circ}\right)$ & Tilt $\left(^{\circ}\right)$ & Energy $(\mathrm{kcal} / \mathrm{mol})$ & Pore lining \\
\hline T-Seq1 & 2.375 & 320 & 9 & -4710.7 & TMD2 \\
T-Seq2 & $2 . .5$ & 180 & 36 & -4724.8 & TMD2 \\
T-Sim & 2.10 & 190 & 24 & -4294.2 & TMD3 \\
T-Seq1-L & 2.025 & 310 & 24 & -5596.9 & TMD2 \\
T-Seq2-L & 2.20 & 150 & -36 & -6136.7 & TMD2 \\
T-Sim-L & 2.20 & 305 & 21 & -5543.0 & TMD2 \\
\hline
\end{tabular}

are shown individually. For T-Seq1 the RMSD of all TMDs are within the same range of $0.2-0.3 \mathrm{~nm}$. (Fig. 5a, II). The RMSD values for TMD1 and TMD3 of T-Seq2 are higher ( $\sim 0.24 \mathrm{~nm}$ for TMD1, and $\sim 0.26 \mathrm{~nm}$ for TMD3) than for TMD2 ( 0.15) (Fig. 5a, III). The same situation can also be found in T-Sim with TMD3 pore lining (RMSD $0.19 \mathrm{~nm})$ and TMD1 $(\sim 0.23 \mathrm{~nm})$ and TMD2 $(\sim 0.25 \mathrm{~nm})$ at the outside of the bundle (Fig. 5a, IV). Super positioning the final structure (green, Fig. 6a-c) with the initial structures (red, Fig. 6a-c) indicates the result of the RMSD calculations in as much as the bundles do not deviate from each other very much, but show a pattern that the non-pore lining TMDs experience larger deviation from the initial structure than the pore lining residues.
Fig. 4 Tetramers according to the assembly protocols without loops: T-Seq1 (a), T-Seq2 (b),

T-Sim (c); tetramers assembled with loops added after monomer assembly: T-Seq1-L (d),

T-Seq2-L (e), T-Sim-L (f) a
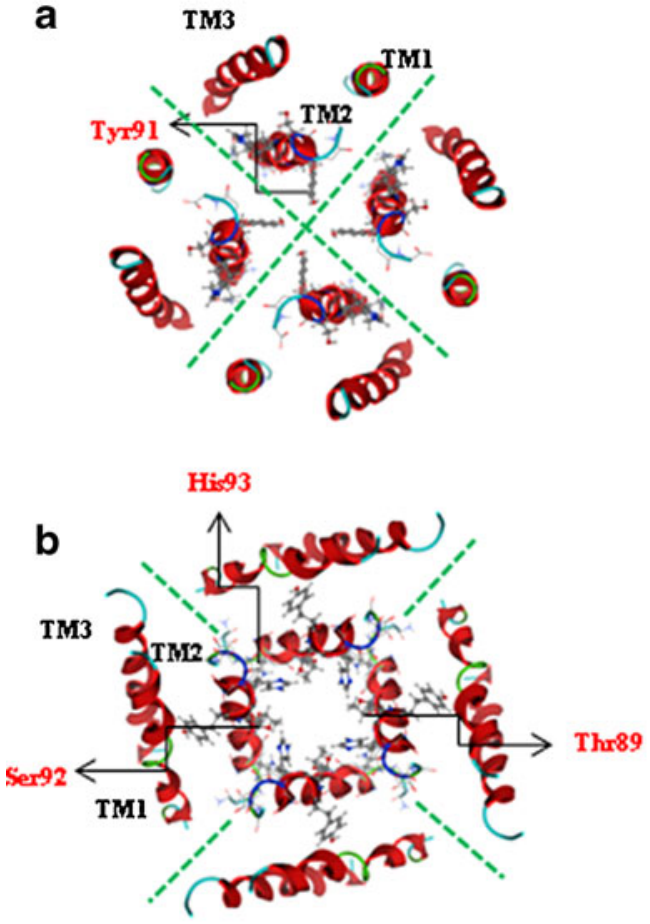

C

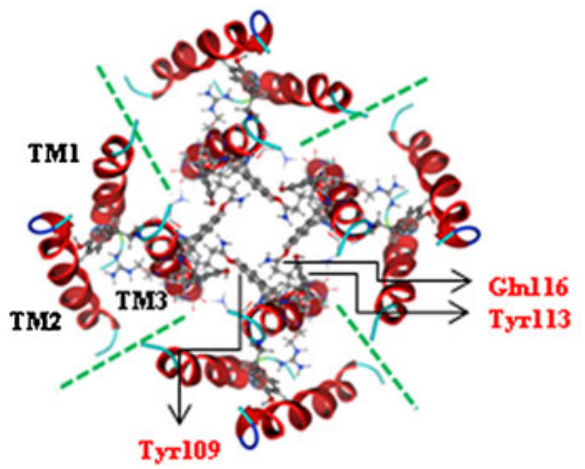

d
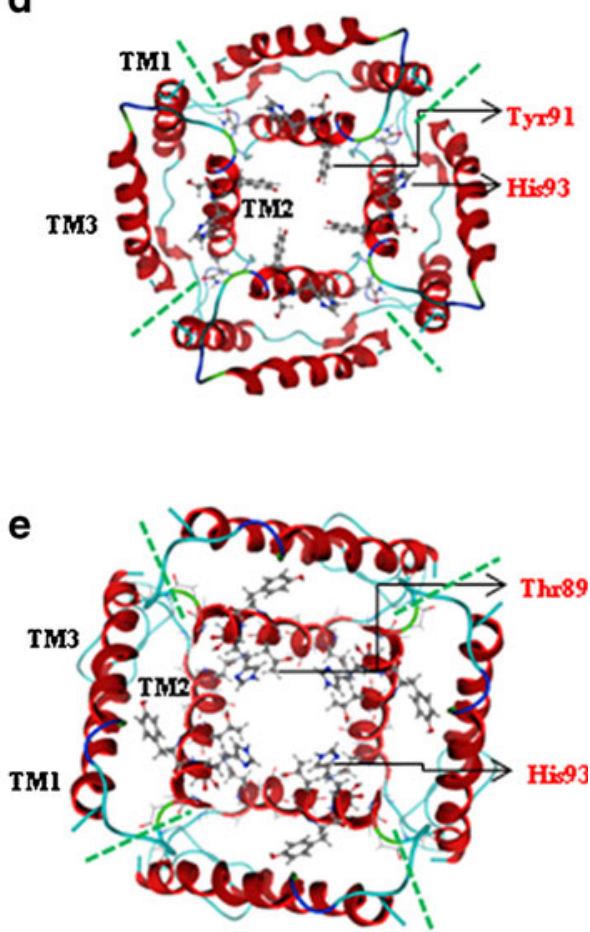

f

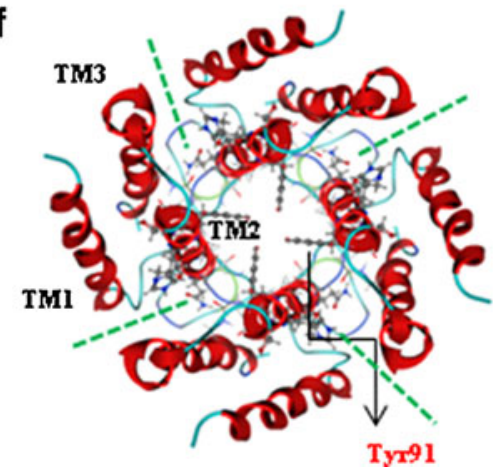


RMSD values for the bundles with loops indicate deviations in the range of $0.35-0.5 \mathrm{~nm}$ (Fig. 5b, I). TSeq1; The large deviation is due to TMD1 in T-Seq1-L ( $0.43 \mathrm{~nm})$ and T-Seq2-L $(\sim 0.45 \mathrm{~nm})$ shown in Fig. $5 \mathrm{~b}$, II and III. TMDs 2 and 3 in both bundles almost not deviate from each other. The RMSD values for TMDs of T-Sim-L are in a close range $(0.24 \sim 0.30 \mathrm{~nm})$ (Fig. $5 \mathrm{~b}$, IV). There is a tendency for increased values in the order TMD2 < TMD1 < TMD3. Indicating TMD2, which is pore lining to exhibit the lowest deviation. The superposition of the initial and final bundle for the structures with loops reflect the RMSD data that at least one of the TMD outside the pore has a large deviation, most likely TMD1. Less deviation is observed for the second outer TMD and the pore lining TMD.

\section{Pore-radius analysis}

The pore radii of the first 25 structures (covering five hundred pico second simulation in steps of 20 ps, Fig. 7, light lines) are compared to the radii derived toward the end of the simulation, taking the last 25 structures in steps of 20 ps for all the bundles (Fig. 7, thick lines). For T-Seq1 bundle, inside the membrane there are three local minima in the initial structure (Fig. 7a, thin line), caused by rings of Phe-87 (at $-1.5 \mathrm{~nm}$ ), Tyr-91 (at $-0.5 \mathrm{~nm}$ ), and Leu-94 (at $0.6 \mathrm{~nm}$ ). The minimum pore radius is at Tyr-91, about $0.02 \mathrm{~nm}$. Toward the end of the simulation only the region around Leu-94 is closed causing a minimum pore radius of $0.05 \mathrm{~nm}$. For T-Seq2 (Fig. 7b), minima are caused by His93 at position $0.3 \mathrm{~nm}$ and Leu-96 (at $1.2 \mathrm{~nm}$ ). The minimum pore radius is at His-93, with about $0.04 \mathrm{~nm}$. After $20 \mathrm{~ns}$ the pore radius is calculated to be around $0.02 \mathrm{~nm}$ around both, His-93 and Leu-96. T-Sim minima cover the stretch along Gln-116 (position $-0.7 \mathrm{~nm}$ ), Tyr113 (position $-0.1 \mathrm{~nm}$ ), and Tyr-109 (position $1.0 \mathrm{~nm}$ ) in the initial configuration (Fig. 7c). The minimum pore radius is at Gln-116, with about $0.026 \mathrm{~nm}$. At the end of the simulation the entire stretch around Tyr-113 to Gln116 retains a narrow pore passage with even Phe-105 at position $1.75 \mathrm{~nm}$ closing in at the mouth of the pore inducing almost a closure of the pore (minimum radius $0.03 \mathrm{~nm}$ ).

The starting structure of T-Seq1-L bundle indicates a very narrow passage around Tyr-91 at position $0.45 \mathrm{~nm}$ with a minimum radius of $0.04 \mathrm{~nm}$ (Fig. $7 \mathrm{~d}$, thin line). After $20 \mathrm{~ns}$ the whole pore collapses and the minimum pore radius around Tyr-91 is at $0.013 \mathrm{~nm}$ (Fig. $7 \mathrm{~d}$, thick line). In T-Seq2-L a smallest pore radius is found around Leu-85 (position $-1.1 \mathrm{~nm}$ ) with about $0.15 \mathrm{~nm}$ (Fig. 7e). Two more space confinements are around Thr- 89 (position $0.0 \mathrm{~nm}$ ) with a radius of $0.2 \mathrm{~nm}$ and His-93 (position $0.85 \mathrm{~nm}$ ) adopting a radius of $0.4 \mathrm{~nm}$. During the simulation pore
Fig. 5 Root mean square deviation (RMSD) of the $\mathrm{C} \alpha$ backbones of the bundle structures referring to the starting structure. T-Seq1 (gray), T-Seq2 (light gray) and T-Sim (black in aI) are shown. The respective RMSD values for the individual TMDs of each simulation (TMD1 in light gray, TMD2 in gray, TMD3 in black) are shown separately (aIIIV). RMSD values of the bundles including the loops are shown for TSeq1-L, TSeq2-L and T-Sim-L (b). Color coding and arrangement of the panels like in (a)

confines around Thr- 89 at around $-0.2 \mathrm{~nm}$ with a radius of $0.04 \mathrm{~nm}$. For T-Sim-L the minimum pore radius of initial average structure is located at Tyr-91 at position $0.8 \mathrm{~nm}$ with a radius of $0.04 \mathrm{~nm}$ (Fig. 7f). At the end of the simulation the tyrosines have closed the pore. Constriction is at $1.0 \mathrm{~nm}$ due to the flexibility of the aromatic side chains.

\section{Water molecules trajectories analysis}

Water molecules do show three different kind of behaviors, (i) they get trapped in the pore found for T-Seq1 (data not shown), T-Sim-L, and T-Seq2-L (ii) they enter the pore on either side and escape on the same side found especially for T-Seq2 and T-Sim, and T-Seq1-L (iii) water molecules traverse the pore completely as found only for T-Seq2-L (5 water molecules in total). Adding the loop to the bundles results in pores with the likely hood of enabling a water passage across the bundle.

\section{Discussion}

\section{Biological considerations}

Experiments with $3 \mathrm{a}$ have identified the protein as a tetrameric unit enabling ion flux across the plasma membrane of infected Xenopus oocytes [4] which can also be inhibited by emodin [37]. Based on the experimental evidence the idea is to suggest a potential channel assembly based on experience in assembling smaller channel forming proteins $[15,31,38-40]$. Similar to other channel forming proteins such as Vpu from HIV-1 [41], also $3 \mathrm{a}$ is reported to interact with host factors [42]. Therefore these proteins are also called accessory proteins. The term implies that the presence of the protein helps the virus, but the virus is not dependent on it. Based on electrophysiological measurements the formation of channels cannot be ruled out at this stage and has to be considered also for drug development.

Considerations about the assembly protocol

A specific protocol is used to generate the tertiary structure of the TMD of a membrane protein [31]. It takes the secondary structural elements of the TMD which are helices 

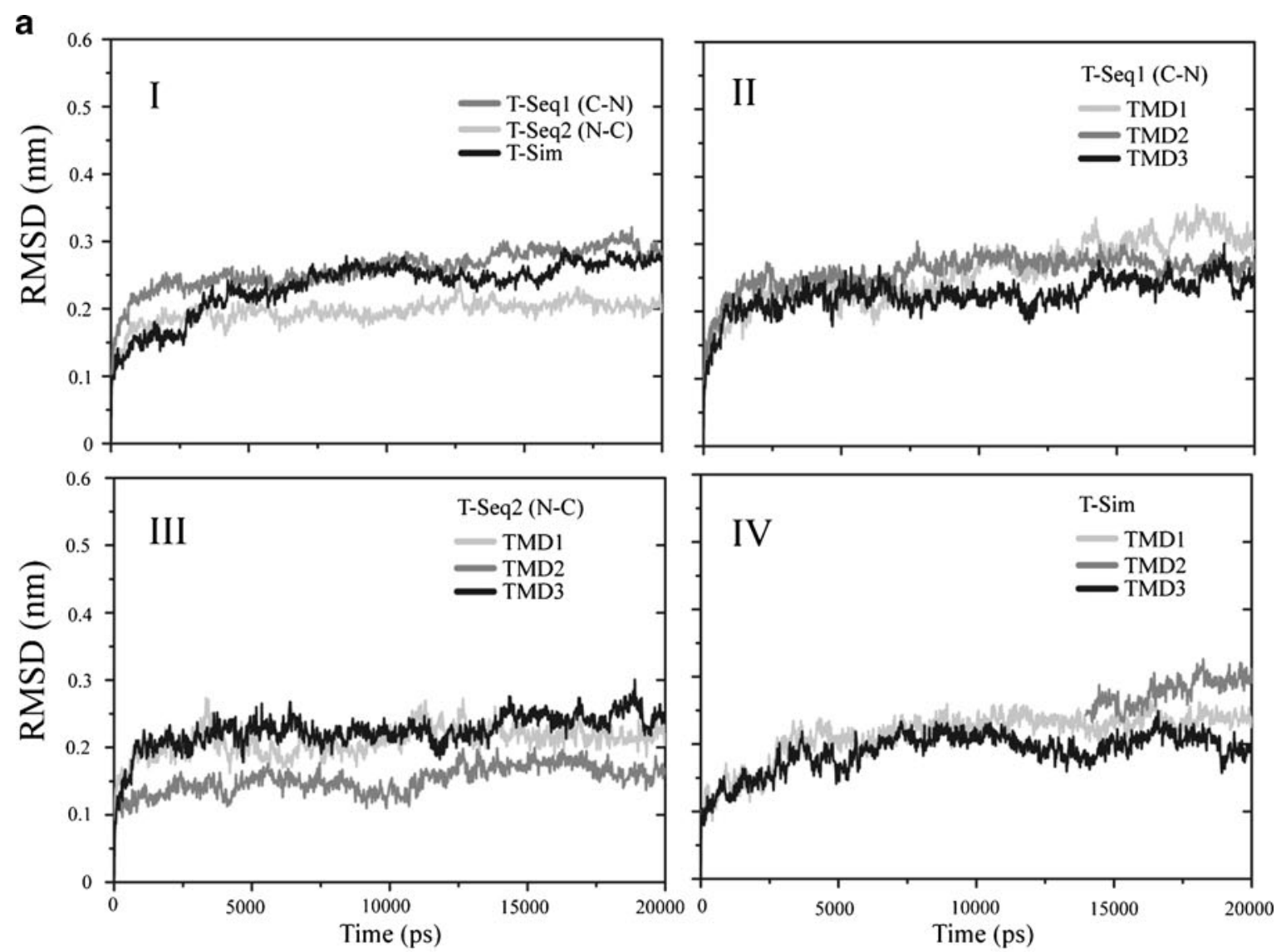

b
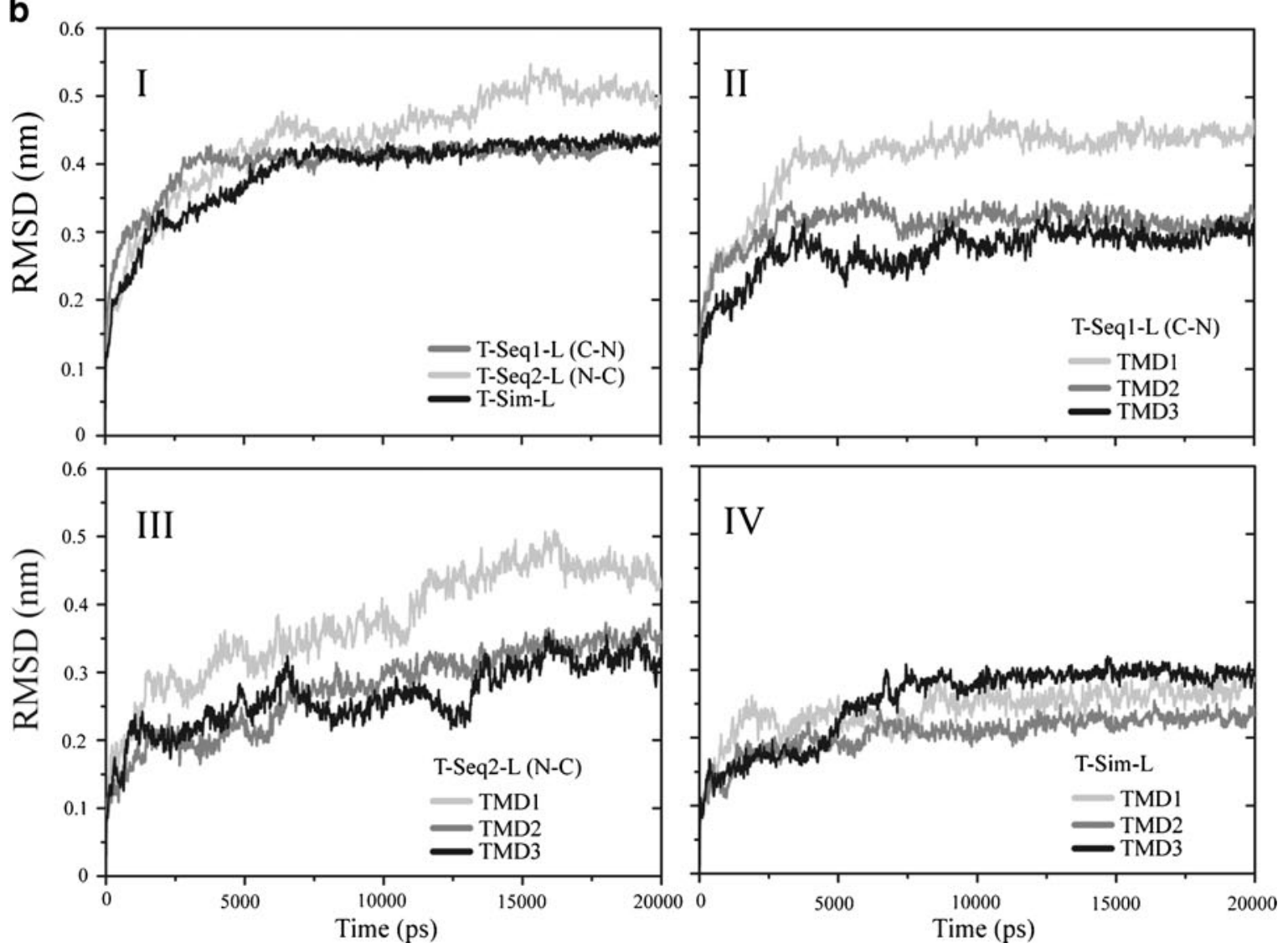
Fig. 6 Models of T-Seq1 (a),

T-Seq2 (b) and T-Sim (c),

T-Seq1-L (d), T-Seq2-L (e) and

T-Sim-L (f) are shown in their starting conformation (green) and after 20 ns of MD simulation (red)

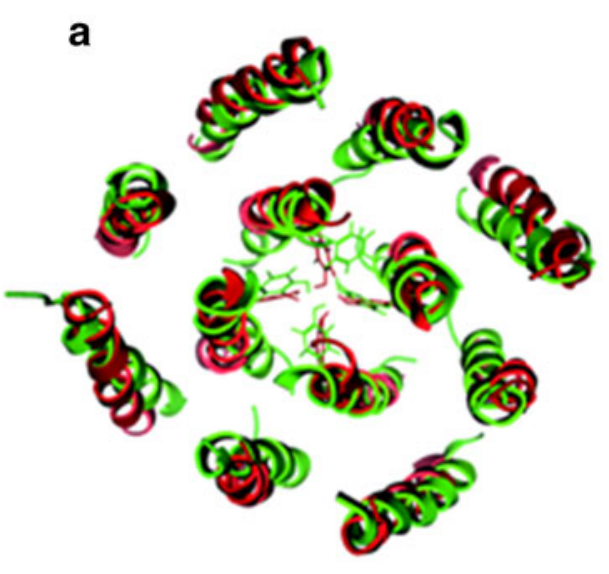

d

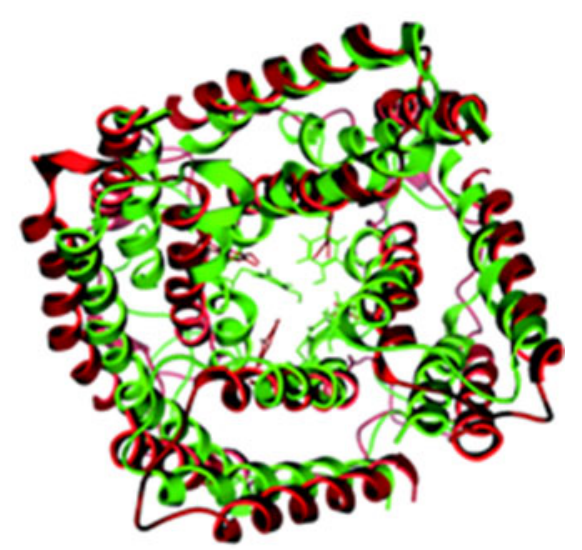

b

e
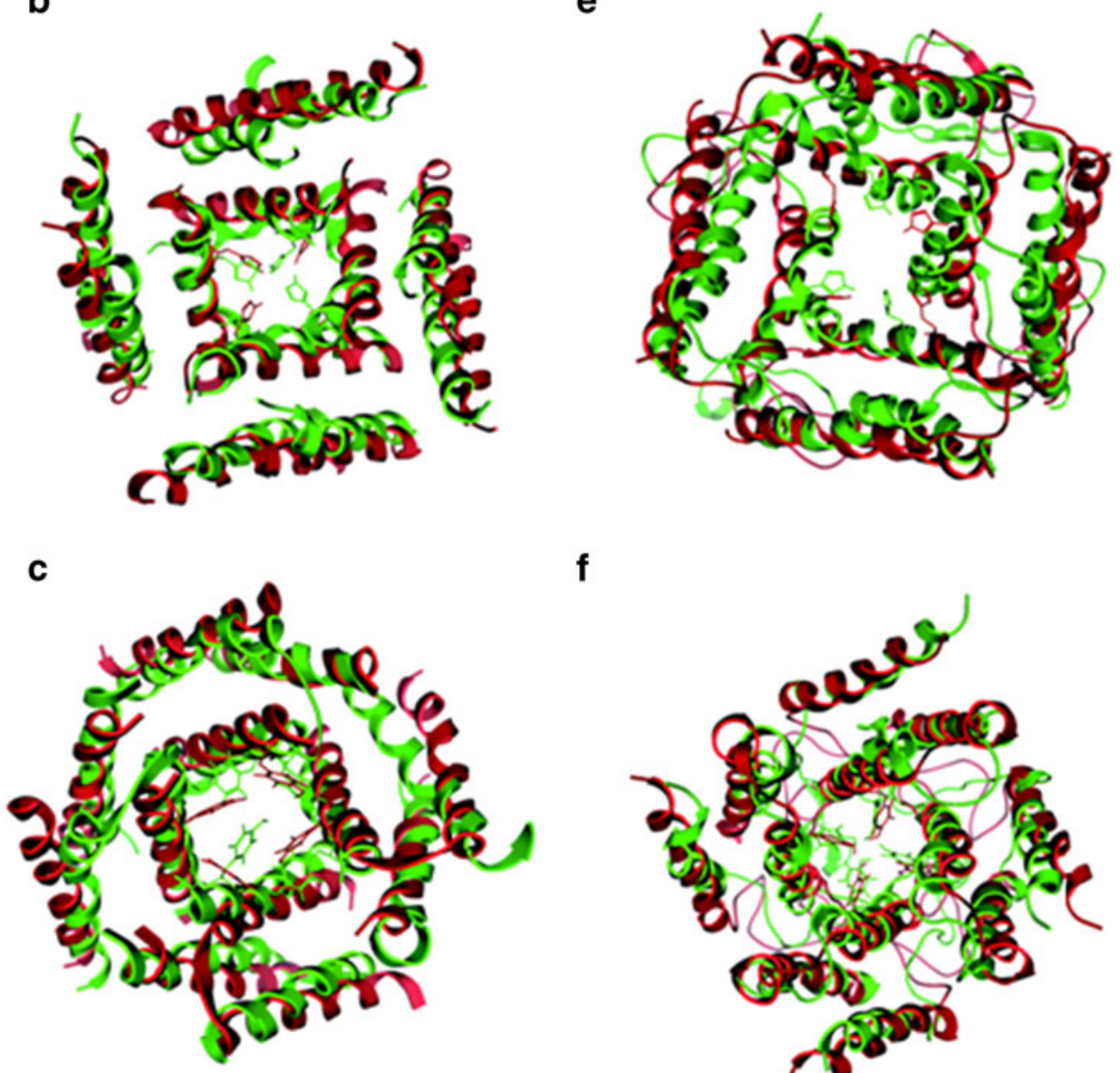

$\mathbf{f}$

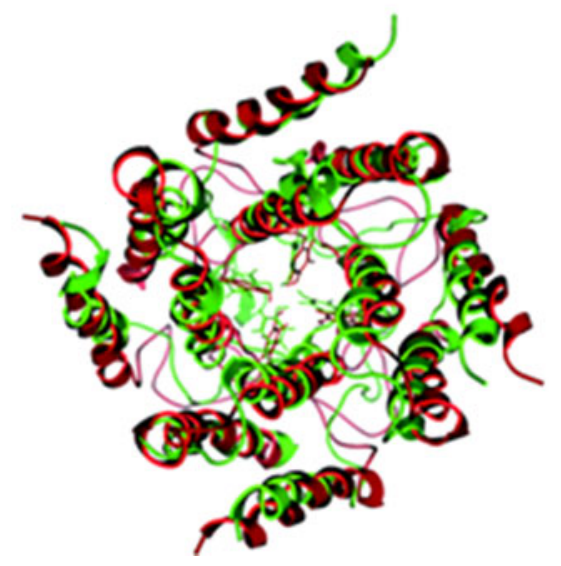

in this study and screens the interactions of these helices in $2 \mathrm{D}$. Upon each positioning in $2 \mathrm{D}$ the potential orientation of the side chains at each position is taken from rotational library integrated in the program MOE. Each position is allowed to relax via energy minimization prior to energy calculations. Screening in 3D with a rigid body approach as done by other programs (e.g., [43]) has been omitted due to biological reasons as vertical movement of TMDs within a lipid bilayer is very much limited. It is anticipated that, e.g., adjustment to lipid dynamics is rather achieved by changes in tilt angles which is taken care of in the present assembly approach. With the assembly protocol at hand it is possible to evaluate different kind of routes of assembly.

Assembly of membrane proteins and especially the TMDs can go two ways, either they are done 'ab initio', or they are done taking biological considerations into account. The first approach has been demonstrated to deliver results on other viral channel proteins which are in agreement with experiments [31]. Another approach is to assume biological pathways such as the TMDs once released from the translocon assembly stepby-step, in a sequential way. After another short period of time they find the other monomers to assemble finally in the 
Fig. 7 Pore radii calculated using the software HOLE [56]. The values of the first 25 structures, covering 500 ps simulation in steps of $20 \mathrm{ps}$, are averaged and depicted in light lines. A similar average has been calculated covering the last $500 \mathrm{ps}$ of the simulations (thick lines). Models of T-Seq1 (a), T-Seq 2 (b) and T-Sim (c), T-Seq1-L (d), T-Seq2-L (e) and T-Sim-L (f) are shown
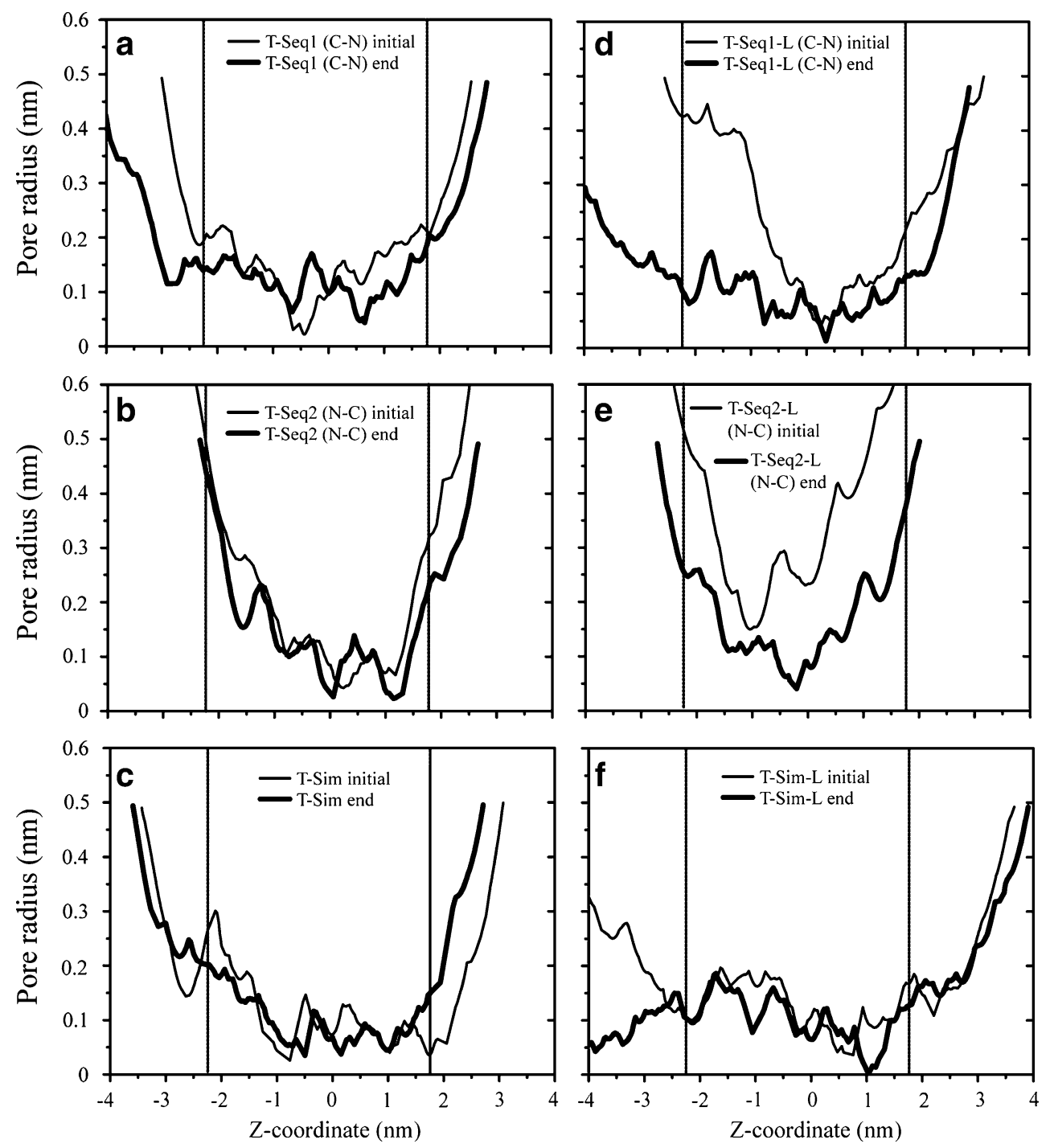

functional form. In the protocol described at the stage of assembling the tetramer, the concerted protocol is used. A sequential assembly at this stage, however, does not need to be ruled out. Assembly at this level may follow another biological pathway: The monomer can be in equilibrium between "free" and "raft" or "protein attached" states. Raft association has been proposed for M2 [44] and Vpu [45]. Thus also a raft attached state could be the seed for assembly of more monomers. In addition, the same scenario could be followed attaching to a host factor first or even to generate the covalent link between two of these monomers. All of these routes would be necessary to be taken into account. In the lack of any information about these scenarios the concerted assembly at this stage seems to be reasonable. It is assumed that the approach samples all low energy structures which inevitably impose constraints also on the "biological" pathways.

During the sequential assembly two routes are assumed, from the $\mathrm{C}$ to $\mathrm{N}$ termini and the opposite direction. The assembly route from $\mathrm{C}$ to $\mathrm{N}$ termini reflects the idea that TMD1 escapes the translocon first, 'diffuses' away and allows the other two TMDs to be assembled first. This idea may be synonymous for a "loose" packing of the helices. The opposite route takes its rationale from the consideration that TMD1 may be retained near or at the translocon despite the longer loop between the TMD1 and the consecutive TMD2. Consequently TMD2 is manufactured and assembled with TMD1, followed by the assembly of TMD3. This route could be seen as a "constraint" packing.

\section{Bundle and pore structure}

All bundles in common are a pore lining TMD2 except for the bundle without loops built from the monomer using the simultaneous assembly protocol (T-Sim). TMD2 as the pore lining domain creates a Tyr-only (using Seq1 and Sim with loops) and a His/Tyr (Seq2) motif within the pore, whilst TMD3 creates a Tyr/Gln motif (using Sim without loops). A histidine within a pore has been found for M2 from influenza A [46, 47] and is proposed for $\mathrm{p} 7$ from HCV [39]. Tyrosines lining the pore may rather be unusual. Tyrosines 
may catch a cation via cation $/ \pi$ interaction [48] and impose an ion trap along the pathway. Together with histidine this energy we think may be overcome making the bundle derived from Seq2 protocol the most likely one. Similar to M2 in respect to the number of monomers it seems to be likely that 3 a may even be conducting protons rather than ions or should at least be $\mathrm{pH}$ dependent in its mechanism of function similar to the same proposal for $\mathrm{p} 7$ [39]. The Tyr/ Gln motif may adopt the same mechanism as assumed for the bundle with the Tyr/His motif. At this stage it cannot be discriminated which motif would be the most effective one in respect to ion or proton conductance.

In a configuration of TMD2 the pore lining domain and TMD3 at the outside allows conformational freedom to enable covalent Cys-Cys linkage within the extramembrane part (Cys-133 in [4]) of two monomers without constraining the packing of the overall bundle in respect to the pore lining configuration.

Previously we have assembled in simultaneous mode, and got TMD3 pore lining. With a 'biological route' we suggest TMD2 pore lining.

\section{Bundle dynamics}

The results from the short equilibration dynamics of the bundles without loops deliver the picture that the inner helices of the bundles remain constrained relative to the TMDs at the outside of the bundle facing the lipid environment (T-Seq2, T-Sim). In all simulations of the bundles generated with the loops TMD1 shows the largest deviation from the starting structure whilst the values for TMD3 go almost in concord with those for TMD2 (T-Seq1L, T-Seq2-L). This suggests that the assembly protocol delivers a structurally stable pore motif whilst the outer TMDs still need an extended equilibration. With the outer TMDs adjusting during the MD simulation, the pore lining TMDs are unaffected by the dynamics of the outer TMDs for the bundles without loop. It further implies that the short loop between TMD2 and TMD3 restrains the dynamics of TMD3. The findings suggest that the outer TMDs could be susceptible and allowing for some dynamics without affecting the inner helices.

In respect to the dynamics of the TMDs, analysis of the temperature (B) factor a series of crystal structures of known channel and pore proteins reveals a pattern in which helical TMDs surrounded by other helical TMDs show lower temperature (B) factors [49-53]. In the case of the mechanosensitive channel [54], the closed state model of pentameric ligand gated ion channel (LGIC) [49] and the glutamate receptor [51] a similar gradient of the temperature (B) factor for the TMDs across the membrane exists. For the mechanosensitive channel lower factors are found in the center of the TMDs and higher factors to both sides whilst for pLGIC and the glutamate receptor the temperature factor decreases within the TMDs toward the extramembrane domain of the channel. These data suggest that central TMDs adopt some rigidity whilst outer TMDs allow for some dynamics.

\section{Water molecules in the pore}

During the short equilibration the pore radius in all models fall below the radius of a sodium ion (e.g., $0.1 \mathrm{~nm}$ [55]) implying sever constraints onto the putative passage of ions. Only the bundle generated according to Seq2 with loops (T-Seq2-L) allows some water molecules to traverse. The water molecules remain on the level of the ring of His93 for several ns before they leave the place in the other direction. All bundles have in common that not only hydrophilic stretches but also the rings of tyrosine impose special constrains on the passage through the pore. The findings for T-Seq2-L with water molecules crossing the pore and tyrosines restricting the pore it is likely that T-Seq2-L is the bundle of choice in this study. It may further underpin the suggestion of $3 \mathrm{a}$ to be proton conducting or at least sensitive to and triggered by the $\mathrm{pH}$ of the environment.

The lack of a continuous water column, which exists over the entire simulations in any of the bundles, imposes the question what are the necessities to generate and maintain such a column. At this stage it is speculated that ions are necessary to "stabilize" the pore and similar to the finding for the $\mathrm{K}^{+}$-channel are essential for ion conductance.

At this stage any conductance of substrates has to be ruled out making the protein rather more ion channel like than pore like.

\section{Role of the loops}

Throughout the protocol we do not find a major impact of the loops on the structural modeling. The only exception is that in T-Sim TMD3 is suggested to be pore lining. However in the light of missing dynamics of the loops during assembly T-Sim may be rather a conformational exception. This underpins the idea that structural features can be independently modeled from the rest of the protein. Any extramembrane parts can be added after assembly. Possibly proteins are built in either of the environments, hydrophilic or hydrophobic, and then assembled. This leaves the question of the dynamics of the linker region between these two segments open for debate.

It is evident that the bundles with loops added have lower energy than those without loops. This is an indication that the addition of the loops improves the stability of the bundle. 


\section{Conclusions}

Modeling of a membrane protein from ab initio conditions delivers a reasonable model of 3 a prior to experimental calculations. Model generation is based on a combination of pure energetic considerations and the implementation of biological manufacturing praxis. As expected the computational approach delivers not a single result but the plurality can be reduced by considering further calculations on the proposed structural models. At the current level of calculations it is suggested that $3 \mathrm{a}$ adopts a bundle structure with TMD2 facing the putative pore albeit a TMD3 pore lining cannot be completely ruled out. The configuration delivers a Tyr and/or His motif to line the pore. It is further concluded based on the low pore radii generated by the protocol that ions embedded within the pore may be necessary to stabilize the pore and enabling ion flux. With histidine as part of the pore motif, 3a may also be a proton channel or at least sensitive or triggered by the $\mathrm{pH}$ around it. The pore architecture as presented would rule out $3 \mathrm{a}$ to be a substrate conducting pore.

Short equilibration runs using MD simulations are indicative for an excellent packing of the inner helices. The outer TMDs still need an extended equilibration to adjust for the bundle architecture.

With the more complex architecture $3 \mathrm{a}$ must be able to harbor a more precise activation mechanism. With this the role of the channel protein could be more specific and triggered by a more specific modulation mechanism underpinning is status as an ion/proton channel rather than a pore.

Acknowledgments WBF acknowledges National Yang-Ming University, the government of Taiwan and the National Science Council of Taiwan (NSC) for financial support. Thanks to D. Willbold (Jülich, D) for valuable discussions. We thank the National Center for High-Performance Computing of Taiwan (www.nchc.org.tw) for providing computer time.

\section{References}

1. Marra MA, Jones SJM, Astell CR, Holt RA, Brooks-Wilson A, Butterfield YSN, Khattra J, Asano JK, Barber SA, Chan SY, Cloutier A, Coughlin SM, Freeman D, Girn N, Griffith OL, Leach SR, Mayo M, McDonald H, Montgomery SB, Pandoh PK, Petrescu AS, Gordon Robertson A, Schein JE, Siddiqui A, Smailus DE, Stott JM, Yang GS, Plummer F, Andonov A, Artsob H, Bastien N, Bernard K, Booth TF, Bowness D, Czub M, Drebot M, Fernando L, Flick R, Garbutt M, Gray M, Grolla A, Jones S, Feldmann H, Meyers A, Kabani A, Li Y, Normand S, Stroher U, Tipples GA, Tyler S, Vogrig R, Ward D, Watson B, Brunham RC, Krajden M, Petric M, Skowronski DM, Upton C, Roper RL (2003) The genome sequence of the SARS-Associated Coronavirus. Science 300:1399-1404

2. Zeng R, Yang R-F, Shi M-D, Jiang M-R, Xie Y-H, Ruan H-Q, Jiang X-S, Shi L, Zhou H, Zhang L, Wu XD, Lin Y, Ji YY,
Xiong L, Jin Y, Dai EH, Wang XY, Si BY, Wang J, Wang HX, Wang CE, Gan YH, Li YC, Cao JT, Zuo JP, Shan SF, Xie E, Chen SH, Jiang ZQ, Zhang X, Wang Y, Pei G, Sun B, Wu JR (2004) Characterization of the 3a protein of SARS-associated coronavirus in infected Vero E6 cells and SARS patients. J Mol Biol 341:271-279

3. Tan YJ, Teng E, Shen S, Tan THP, Goh PY, Fielding BC, Ooi EE, Tan HC, Lim SG, Hong W (2004) A novel severe acute respiratory syndrome coronavirus protein, U274, is transported to the cell surface and undergoes endocytosis. J Virol 78:6723-6734

4. Lu W, Zheng BJ, Xu K, Schwarz W, Du L, Wong CKL, Chen J, Duan S, Deubel V, Sun B (2006) Severe acute respiratory syndrome-associated coronavirus 3 a protein forms an ion channel and modulates virus release. Proc Natl Acad Sci USA 103:12540-12545

5. Chen CY, Ping YH, Lee HC, Chen KH, Lee YM, Chan YJ, Lien TC, Jap TS, Lin CH, Kao LS, Chen YMA (2007) Open reading frame $8 \mathrm{a}$ of the Human severe acute respiratory syndrome coronavirus not only promotes viral replication but also induces apoptosis. J Infect Dis 196:405-415

6. Fischer WB, Sansom MSP (2002) Viral ion channels: structure and function. Biochim Biophys Acta 1561:27-45

7. Fischer WB, Hsu HJ (2011) Viral channel forming proteins modelling the target. Biochim Biophys Acta 1808:561-571

8. Fischer WB, Krüger J (2009) Viral channel forming proteins. Int Rev Cell Mol Biol 275:35-63

9. Allen H, McCauley J, Waterfield M, Gethering M (1980) Influenza virus RNA segment 7 has the coding capacity for two polypeptides. Virology 107:548-551

10. Holsinger LJ, Nichani D, Pinto LH, Lamb RA (1994) Influenza A virus M2 ion channel protein: a structure-function analysis. J Virol 68:1551-1563

11. Mould JA, Li HC, Dudlak CS, Lear JD, Pekosz A, Lamb RA, Pinto LH (2000) Mechanism for proton conduction of the $\mathrm{M}_{2}$ ion channel of influenza A virus. J Biol Chem 275:8592-8599

12. Lin T, Schroeder C (2001) Definitive assignment of proton selectivity and attoampere unitary current to the M2 ion channel protein of influenza A virus. J Virol 75:3647-3656

13. Schubert U, Ferrer-Montiel AV, Oblatt-Montal M, Henklein P, Strebel K, Montal M (1996) Identification of an ion channel activity of the $\mathrm{Vpu}$ transmembrane domain and its involvement in the regulation of virus release from HIV-1-infected cells. FEBS Lett 398:12-18

14. Ewart GD, Sutherland T, Gage PW, Cox GB (1996) The Vpu protein of human immunodeficiency virus type 1 forms cationselective ion channels. J Virol 70:7108-7115

15. Chen CC, Krüger J, Sramala I, Hsu HJ, Henklein P, Chen YMA, Fischer WB (2011) ORF 8a of severe acute respiratory syndrome coronavirus forms an ion channel: experiments and molecular dynamics simulations. Biochim Biophys Acta 1808:572-579

16. Griffin SDC, Beales LP, Clarke DS, Worsfold O, Evans SD, Jäger J, Harris MPG, Rowlands DJ (2003) The p7 protein of hepatitis C virus forms an ion channel that is blocked by the antiviral drug, amantadine. FEBS Lett 535:34-38

17. Pavlovic D, Neville DCA, Argaud O, Blumberg B, Dwek RA, Fischer WB, Zitzmann N (2003) The hepatitis C virus p7 protein forms an ion channel that is inhibited by long-alkyl-chain iminosugar derivatives. Proc Natl Acad Sci USA 100:6104-6108

18. Agirre A, Barco A, Carrasco L, Nieva JL (2002) Viroporinmediated membrane permeabilization. Pore formation by nanostructural poliovirus 2B protein. J Biol Chem 277:4043440441

19. de Jong AS, Wessels E, Dijkman HBPM, Galama JMD, Melchers WJG, Willems PHGM, van Kuppeveld FJM (2003) Determinants for membrane association and permeabilization of the coxsack- 
ievirus $2 \mathrm{~B}$ protein and the identification of the Golgi complex as the target organelle. J Biol Chem 278:1012-1021

20. Pervushin K, Tan E, Parthasarathy K, Lin X, Jiang F-L, Yu D, Vararattanavech A, Soong TW, Liu D-X, Torres J (2009) Structure and inhibition of the SARS Coronavirus envelope protein ion channel. PLoS Pathog 5:e1000511

21. Cook GA, Zhang H, Park SH, Wang Y, Opella SJ (2011) Comparative NMR studies demonstrate profound differences between two viroporins: $\mathrm{p} 7$ of HCV and Vpu of HIV-1. Biochim Biophys Acta 1808:554-560

22. Popot JL, Engelman DM (1990) Membrane protein folding and oligomerization: the two-stage model. Biochemistry 29:4031-4037

23. Engelman DM, Chen Y, Chin CN, Curran AR, Dixon AM, Dupuy AD, Lee AS, Lehnert U, Matthews EE, Reshetnyak YK, Senes A, Popot JL (2003) Membrane protein folding: beyond the two stage model. FEBS Lett 555:122-125

24. White SH, Wimley WC (1999) Membrane protein folding and stability: physical principles. Annu Rev Biophys Biomol Struct 28:319-365

25. Sansom MSP, Kerr ID (1993) Influenza virus $M_{2}$ protein: a molecular modelling study on the ion channel. Protein Eng 6:65-74

26. Kukol A, Adams PD, Rice LM, Brunger AT, Arkin IT (1999) Experimentally based orientational refinement of membrane protein models: a structure for the influenza A M2 $\mathrm{H}^{+}$channel. J Mol Biol 286:951-962

27. Cordes F, Kukol A, Forrest LR, Arkin IT, Sansom MSP, Fischer WB (2001) The structure of the HIV-1 Vpu ion channel: modelling and simulation studies. Biochim Biophys Acta 1512:291-298

28. Bu L, Im W, Brooks CL III (2007) Membrane assembly of simple helix homo-oligomers studied via molecular dynamics simulations. Biophys J 92:854-863

29. Psachoulia E, Marshall DP, Sansom MSP (2010) Molecular dynamics simulations of the dimerization of transmembrane $\alpha$ helices. Acc Chem Res 43:388-396

30. Bowie JU (2005) Solving the membrane protein folding problem. Nature 438:581-589

31. Krüger J, Fischer WB (2009) Assembly of viral membrane proteins. J Chem Theory Comput 5:2503-2513

32. Wahba K, Schwab D, Bruinsma R (2010) Statistical mechanics of integral membrane protein assembly. Biophys J 99:2217-2224

33. Chandrasekhar I, Kastenholz M, Lins RD, Oostenbrink C, Schuler LD, van Gunsteren WF (2003) A consistent potential energy parameter set for lipids: dipalmitoylphosphatidylcholine as a benchmark of the GROMOS96 45A3 force field. Eur Biophys J 32:67-77

34. Krüger J, Fischer WB (2008) Exploring the conformational space of Vpu from HIV-1: a versatile and adaptable protein. J Comput Chem 29:2416-2424

35. Xiang Z, Soto CS, Honig B (2002) Evaluating conformational free energies: the colony energy and its application to the problem of loop prediction. Proc Natl Acad Sci USA 99:7432-7437

36. Soto CS, Fasnacht M, Zhu J, Forrest L, Honig B (2008) Loop modeling: sampling, filtering, and scoring. Proteins 70:834-843

37. Schwarz S, Wang K, Yu W et al. (2011) Emodin inhibits current through SARS-associated coronavirus 3a protein. Antiviral Res (ahead of print)
38. Cordes FS, Tustian AD, Sansom MS, Watts A, Fischer WB (2002) Bundles consisting of extended transmembrane segments of Vpu from HIV-1: computer simulations and conductance measurements. Biochemistry 41:7359-7365

39. Patargias G, Zitzmann N, Dwek R, Fischer WB (2006) Proteinprotein interactions: modeling the hepatitis $\mathrm{C}$ virus ion channel p7. J Med Chem 49:648-655

40. Patargias G, Barke T, Watts A, Fischer WB (2009) Model generation of viral channel forming $2 \mathrm{~B}$ protein bundles from polio and coxsackie viruses. Mol Membr Biol 26:309-320

41. Skasko M, Tokarev A, Chen C-C et al. (2011) BST-2 is rapidly down-regulated from the cell surface by the HIV-1 protein Vpu: evidence for a post-ER mechanism of Vpu-action. Virology (ahead of print)

42. Narayanan K, Huang C, Makino S (2008) SARS coronavirus accessory proteins. Virus Res 133:113-121

43. Ausiello G, Cesareni G, Helmer-Citterich M (1997) ESCHER: a new docking procedure applied to the reconstruction of protein tertiary structure. Proteins 28:556-567

44. Schroeder C, Heider H, Moncke-Buchner E, Lin TI (2005) The influenza virus ion channel and maturation cofactor M2 is a cholesterol-binding protein. Eur Biophys J 34:52-66

45. Ruiz A, Hill MS, Schmitt K et al. (2010) Membrane raft association of the $\mathrm{Vpu}$ protein of human immunodeficiency virus type 1 correlates with enhanced virus release. Virology (in press)

46. Schnell JR, Chou JJ (2008) Structure and mechanism of the M2 proton channel of influenza A virus. Nature 451:591-595

47. Cady SD, Schmidt-Rohr K, Wang J, Soto CS, DeGrado WF, Hong M (2010) Structure of the amantadine binding site of influenza M2 proton channels in lipid bilayers. Nature 463:689-692

48. Dougherty DA (1996) Cation - $\pi$ interactions in chemistry and biology: a new view of benzene, Phe, Tyr, and Trp. Science 271:163-168

49. Hilf RJC, Dutzler R (2008) X-ray structure of a prokaryotic pentameric ligand-gated ion channel. Nature 452:375-379

50. Hilf RJC, Dutzler R (2009) Structure of a potentially open state of a proton-activated pentameric ligand-gated ion channel. Nature 457:115-119

51. Sobolevsky AI, Rosconi MP, Gouaux E (2009) X-ray structure, symmetry and mechanism of an AMPA-subtype glutamate receptor. Nature 462:745-756

52. Mueller M, Grauschopf U, Maier T, Glockshuber R, Ban N (2009) The structrure of a cytolytic alpha-helical toxin pore reveals its assembly mechanism. Nature 459:726-730

53. Waight AB, Love J, Wang DN (2010) Structure and mechanism of a pentameric formate channel. Nat Struct Biol 17:31-37

54. Steinbacher S, Bass R, Strop P, Rees DC (2007) Structures of the prokaryotic mechanosensitive channels MscL and MscS. Curr Top Membr 58:1-24

55. Stein WD (1990) Channels, carriers and pumps. An introduction to membrane transport. Academic Press Inc, San Diego, CA

56. Smart OS, Neduvelil JG, Wang X, Wallace BA, Sansom MSP (1996) Hole: a program for the analysis of the pore dimensions of ion channel structural models. J Mol Graph 14:354-360 